\title{
Effect of Sintering Temperature and AR Glass Addition towards Physical Properties of Porcelain Clay for Sewer Pipes Application
}

\section{Muhammad Ikhmal Hanapi, Sufizar Ahmad", Hariati Taib and Tan Chee Chen}

Department of Materials and Design Engineering, Faculty of Mechanical and Manufacturing Engineering, Universiti Tun Hussein Onn Malaysia 86400 Parit Raja, Batu Pahat, Johor, Malaysia

Received 7 January 2018; accepted 23 January 2018, available online 3 July 2018

\begin{abstract}
The current work is aimed to investigate significant phase changes at certain sintering temperature with addition of Alkali Resistant (AR) glass in manufacturing clay pipes for sewer application. The use of porcelain clay reinforced with milled AR fiberglass ( $3 \mathrm{wt} \%, 6 \mathrm{wt} \%, 9 \mathrm{wt} \%$ and $12 \mathrm{wt} \%$ ) was determined in this study. Both of raw materials were turned into powder to conduct thermal analysis and produce compact samples. The powder was compacted by uniaxial pressing technique to examine the volume shrinkage. Volume shrinkage analysis was done by measuring the dimension of green body and sintered sample $\left(900^{\circ} \mathrm{C}, 1000^{\circ} \mathrm{C} 1100^{\circ} \mathrm{C}\right.$ and $\left.1200^{\circ} \mathrm{C}\right)$. The image of microstructural morphology was observed by Scanning Electron Microscope. Thermogravimetric graph indicates large amount of mass loss found to be $75 \%$ between $450^{\circ} \mathrm{C}$ to $800^{\circ} \mathrm{C}$ for porcelain and all mixtures. While Differential Thermal graph reveals the endothermic shift was produce at $250^{\circ} \mathrm{C}$. The maximum volume shrinkage was obtained at $1200^{\circ} \mathrm{C}$ which is $31.7 \%$ with $3 \mathrm{wt} \%$ AR glass addition. The microstructural image proved the correlation to volume shrinkage. The presence of glassy phase demonstrates the phenomenon of fluxing agent melts and bonding with porcelain where shrinking particle takes place to construct dense sample.
\end{abstract}

Keywords: Sewer, Porcelain Ceramic, AR Glass, Sintering, Volume Shrinkage

\section{Introduction}

The application of pipes plays a vital role in human society although it is a low profile part in the infrastructure. Choosing material for pipes is indispensable for water and sewage system when designing and installing of pipes takes place [1]. For sewage system, the properties of clay such good thermal mass to retain the consistency of temperature suitably making them establish as an ecological sustainable material in construction [1]. The process to manufacture pipes from clay (ceramic) materials implies a sintering process as final procedure. Sintering becomes a key in ceramic fabrication because it is known as the process of heat treatment to build up strength to the green body of the ceramic [2]. Sintering process generally reduces the volume and increasing densities of the ceramic body due to particle merging. Table 1 summarizes the stages of sintering process.

Despite that, sintering process can result warping and cracking to ceramic body occasionally due to creation of non-uniform shrinkage [3]. Initially, shrinkage creates a mechanical action to ceramic material cause by confinement of stress displacement when changes in ceramic dimension is occurs. The growth of crack can be controlled as well as impact reduction at preliminary shrinkage by inclusion of fibre in low quantity of volumetric body for ceramic material [4]. In other hand, the durability of clay material can be more complex if sophisticated sintering technique applied [5].

Table 1: Stages of particle merging in sintering process [6]

\begin{tabular}{cll}
\hline $\begin{array}{c}\text { Stages of } \\
\text { sintering }\end{array}$ & & \multicolumn{1}{c}{ Description } \\
\hline Initial & i) & Particle rearrangement \\
& ii) & Neck formation of particles \\
\hline & i) & Necking growth \\
& ii) & Grain boundary growth \\
Intermediate & iii) & Higher shrinking of global \\
& body
\end{tabular}

Normally, construction or civil engineering are using Alkali Resistant (AR) glass to reinforce cementitious matrices [7]. This is because AR glass formed a corrosion in the alkaline environment formed which affected long performance and strength stability of composite where mostly exposed to cement hydration [9]. More than that, AR glass can be classified as refractories material because of high content of silica $\left(\mathrm{SiO}_{2}\right)$ and 
Alumina $\left(\mathrm{Al}_{2} \mathrm{O}_{3}\right)$ where extremely essential for low production cost and maintain reliability in thermal industry [8]. This study will reveal the significant change at certain sintering temperature occurs on porcelain clay reinforced with Alkali Resistant (AR) glass powder as a material to manufacture clay pipes for sewer system.

\section{Materials and Method}

The raw materials used for this study involve porcelain clay (Fig. 1 (a)) and AR fiberglass (Fig. 2 (a)). Firstly, raw material was subjected to planetary ball milling at $150 \mathrm{RPM}$ to produce granule powder with average particle size of $90 \mu \mathrm{m}$ as can be seen in Fig 1 (b) and Fig 2 (b). AR glass and porcelain were mixed according to weight percentage at $3 \mathrm{wt} \%, 6 \mathrm{wt} \%, 9 \mathrm{wt} \%$ and $12 \mathrm{wt} \%$.

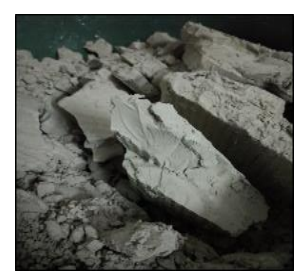

(a)

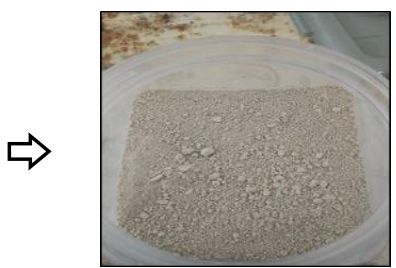

(b)
Fig. 1 Porcelain ceramic preparation: a) clay to b) powder

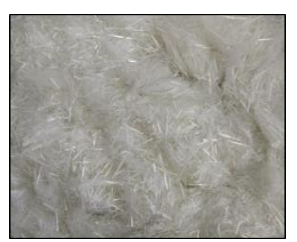

(a)

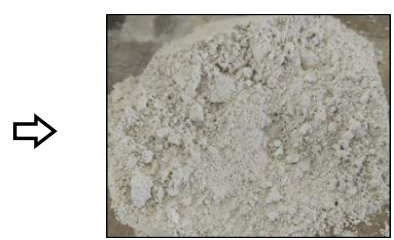

(b)
Fig. 2 AR glass preparation: a) fibre to b) milled powder

For thermal analysis, powder samples were prepared about $10 \mathrm{mg}$ to $11 \mathrm{mg}$ for each composition to be put in the small crucible. Test was conducted by using Mass Flow Unit instrument (Rigaku, Japan). Sample was heated into $1400^{\circ} \mathrm{C}$ with $5^{\circ} \mathrm{C} / \mathrm{min}$ of heating rate.

For volume shrinkage, test was performed according to ASTM C326-09. The analyses sample was fabricated by powder compaction technique with 3 Tons of applied load. Then, the sample was fired at $900^{\circ} \mathrm{C}, 1000^{\circ} \mathrm{C}$, $1100^{\circ} \mathrm{C}$ and $1200^{\circ} \mathrm{C}$ with heating rate of $5^{\circ} \mathrm{C} / \mathrm{min}$ for 2 hours. The dimension of green body (not sintered) and sintered sample was measured with Digital Vernier Caliper (Mitutoyo, Japan). The morphology of samples was analyzed by using Field Emission Scanning Electron Microscope (Hitachi, Japan). Surface of the sample was captured at $15 \mathrm{kV}$ with $3000 \mathrm{X}$ magnification.

\section{Result and Discussion}

This section discusses the result for thermal analysis (TG and DT graph), volume shrinkage and microstructural analysis.

\subsection{Thermal analysis}

Thermogravimetric (TG) analysis was done to determine the percentage of mass loss at elevation temperature with controlled heating rate. While, Differential Thermal analysis (DT) was conducted to identify the heat flow in which display a substantial thermal cycle based on the shift or peak produce from the series.

i. TG Analysis: TG analysis in Fig. 3 providing info on significant phase change, thermal stability and material decomposition through the mass loss shown in the graph.

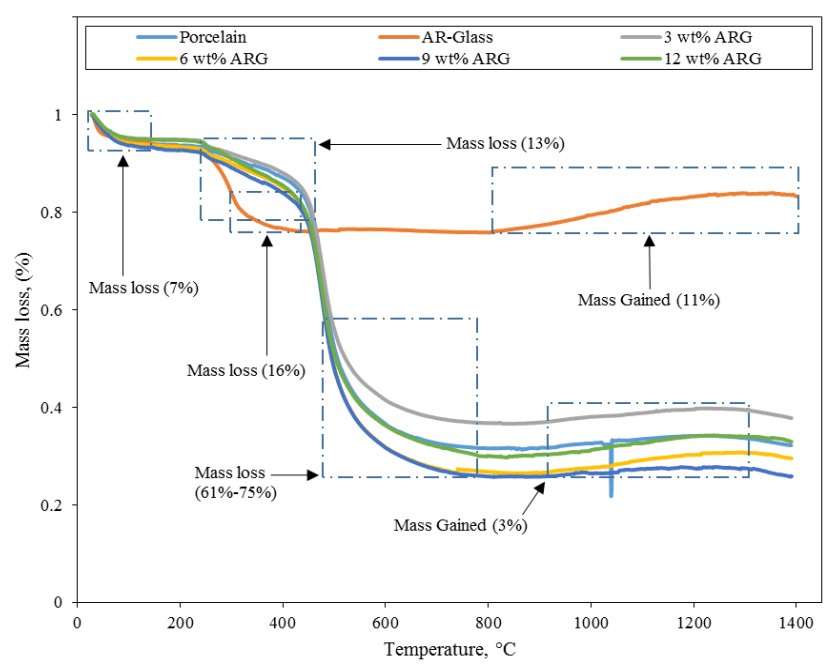

Fig. 3 Graph of Thermogravimetric analysis for all powder samples

The mass loss can be identified based on the curves of each line series. Based on Fig 3, there are four curves which can be denoted as four stages of decomposition/phase change occur to the material. The first stage can be observed at room temperature $\left(32^{\circ} \mathrm{C}\right)$ to $100^{\circ} \mathrm{C}$ where amount of the mass loss found to be $7 \%$ for all sample. From the observation, the mass loss would be due to the loss of water during the vaporization process.

The second stage continues with $13 \%$ of mass loss between $200^{\circ} \mathrm{C}$ and $400^{\circ} \mathrm{C}$ for porcelain clay and all the mixture. This condition can be stated as clay mineral dehydroxylation. Meanwhile, AR glass shown a rapid drop $(16 \%)$ at $250^{\circ} \mathrm{C}$ to $440^{\circ} \mathrm{C}$ due to the break down reaction which indicates formation of sodium silicate to produce a vitrification in sintering [9].

The porcelain and all the mixture continue having a large amount of mass loss at temperature of $450^{\circ} \mathrm{C}$ to $800^{\circ} \mathrm{C}$ (third stage) resulting $61 \%$ to $75 \%$. The remarkable phase change arises at this ranges due to quartz inversion of crystal structure from $\alpha$ to $\beta$ come about $573^{\circ} \mathrm{C}$ typically [10]. Other than that, decomposition of carbonaceous material takes places at temperature of $400^{\circ} \mathrm{C}$ to $800^{\circ} \mathrm{C}$ if the material 
contains carbon [11]. There are no crucial changes occurred at temperature between $750^{\circ} \mathrm{C}$ to $850^{\circ} \mathrm{C}$.

Meanwhile, at $800^{\circ} \mathrm{C}$ (AR glass) and $900^{\circ} \mathrm{C}$ (porcelain and mixture) shows a mass gained. This phenomenon can be referred as firing/sintering process which also mark as essential phase change. At this stage, the ceramic body is densified to form a crystalline structure. Galvao et al., (2015) had mention that the vitrification process contribute the mass gained in sintering due to formation of sodium silicate. The significant shrinkage was produced at this temperature. It is important to maintained the temperature at this stages to induce chemical action as well as fuses matter between flux and main material [12]. Hence, the sample was sintered for 2 hours within $900^{\circ} \mathrm{C}$ to $1200^{\circ} \mathrm{C}$ for shrinkage analysis.

ii. DT Analysis: Fig. 4 provides the graph of DTA that was corresponded with TG graph. The DTA curves can provide the transformation such as melting, crystallization and sublimation.

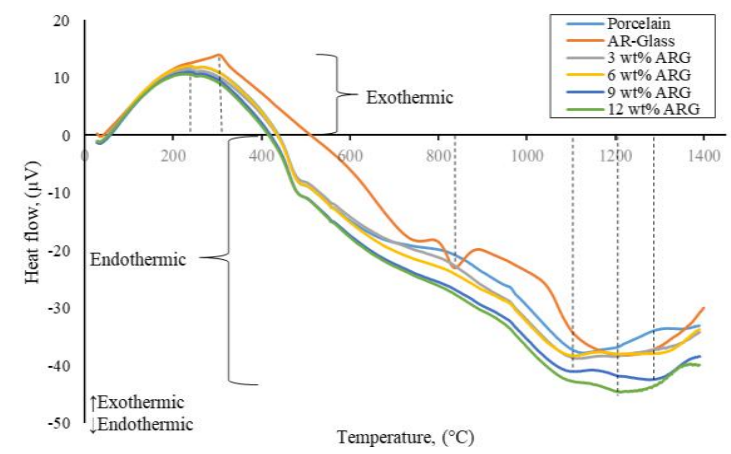

Fig. 4 Graph of Differential Thermal analysis of all powder samples

It can be seen from Fig. 4 that there were two peaks/shifts which can be interpreted as occurrence of exothermic (highest peak) and endothermic (lowest peak). The shift at $250^{\circ} \mathrm{C}$ indicates an exothermic reaction for porcelain and the mixture. The vaporization of water which is the process of release heat (energy) tally to the reduction of mass.

As for AR glass, the highest shift produces at $300^{\circ} \mathrm{C}$ but then having a steep dropped due to rapid presence of liquid phase. The decreasing line between $300^{\circ} \mathrm{C}$ to $1050^{\circ} \mathrm{C}$ exhibit the insignificant phase change occurs. AR glass denotes a small endothermic band at $850^{\circ} \mathrm{C}$ where can be inferred as particle having a melting completion. The incomplete endothermic for all material eventuate at $1150^{\circ} \mathrm{C}$ reveals the process of absorbing heat which can be conclusively stated the complete of densification process.

The lowest peak identified that the melting of fluxing agent which is AR glass and bond with porcelain in which observed as existence of glassy phase.

\subsection{Volume Shrinkage}

Uncontrolled shrinkage of ceramic can produce defects such as crack to the ceramic product. As for this study, volume shrinkage analysis was completed as to determine the shrinkage after sintering. Table 2 reveals the value of volume shrinkage for this study.

Table 2 Result of volume shrinkage for all samples

Percentage of Shrinkage (\%)

\begin{tabular}{cccccc}
\hline $\begin{array}{c}\text { Temp. } \\
\left({ }^{\circ} \mathrm{C}\right)\end{array}$ & $0 \mathrm{wt} \%$ & $3 \mathrm{wt} \%$ & $6 \mathrm{wt} \%$ & $9 \mathrm{wt} \%$ & $12 \mathrm{wt} \%$ \\
\hline 900 & -5.76 & 3.99 & 4.63 & 5.04 & 1.92 \\
\hline 1000 & 0.34 & 8.08 & 9.12 & 10.07 & 10.17 \\
\hline 1100 & 12.85 & 22.17 & 25.30 & 25.65 & 26.62 \\
\hline 1200 & 12.53 & 31.33 & 31.75 & 28.81 & 27.65 \\
\hline
\end{tabular}

The result above illustrates that the shrinkage of $3 \%$ to $10 \%$ produce at $900^{\circ} \mathrm{C}$ and $1000^{\circ} \mathrm{C}$ which can be interpreted as lower volume shrinkage. This is because low sintering temperature would introduce the mineral neck growth and surface diffusion and resulting significant surface area to the sample [13]. The value depicted above proclaims the intermediate stage of sintering occurred. The negative value $(-5.7 \%)$ of shrinkage gained at $900^{\circ} \mathrm{C}$ without addition of AR glass denotes as a volume expansion where particle swelling triggered an incomplete grain growth derives from low viscosity of liquid phase due to low sintering temperature.

The higher volume shrinkage at $1100^{\circ} \mathrm{C}$ and $1200^{\circ} \mathrm{C}$ with ranges $12 \%$ to $31 \%$ affecting in dimension changes. The addition of $6 \mathrm{wt} \% \mathrm{AR}$ glass at $1200^{\circ} \mathrm{C}$ recorded the highest volume shrinkage at $31.75 \%$. Fig. 5 shows the relationship between volume shrinkage and addition of AR glass in which addition of AR glass to the porcelain body indicated remarkable shrinkage. From the trends, the threshold attained between $0 \mathrm{wt} \%$ and others composition.

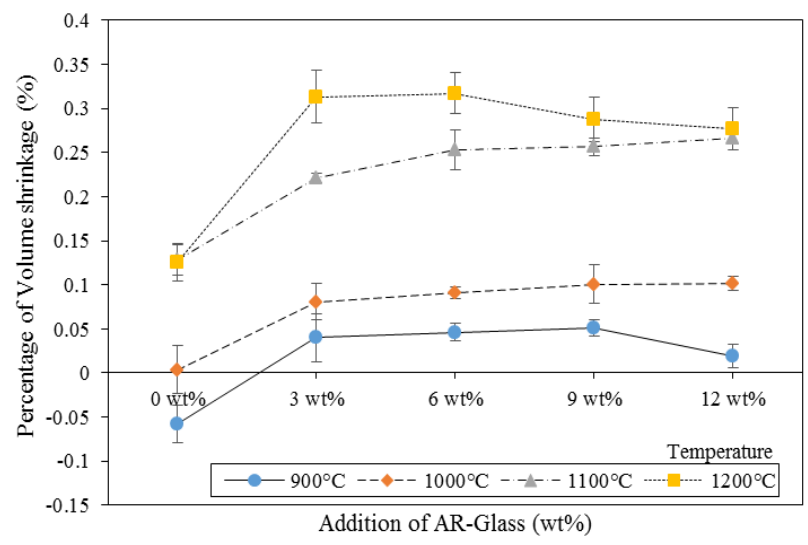

Fig. 5 Graph of volume shrinkage versus AR glass addition 
The increase of shrinkage is signifies vitrification where more particle wetting completion and densification of individual grain occurred [14]. Meanwhile, it can be noticed that the presence of glass phase to the ceramic body derives from AR glass assist the shrinking of the whole ceramic body. However, the increment of AR glass composition does not effect on shrinkage significantly as there is only moderate increase $\left(1000^{\circ} \mathrm{C}\right.$ and $\left.1100^{\circ} \mathrm{C}\right)$ and slight decrease $\left(900^{\circ} \mathrm{C}\right.$ and $\left.1200^{\circ} \mathrm{C}\right)$ for certain composition. As stated by Bernardo et al., the stabilization of shrinkage can be achieved with the presence of inclusion caused by the rises of viscosity mass provide by fluxes. By looking to the result gained, AR glass can be referred as flux where enhance the shrinking of porcelain body.

Based on the line series from Fig. 5, the upper $\left(1200^{\circ} \mathrm{C}\right)$ and lower line series $\left(900^{\circ} \mathrm{C}\right)$ can be interpreted as maximum and minimum condition of volume shrinkage respectively. It can conclusively suppose that high temperature will affect the shrinkage of ceramic body with addition of AR glass. Ceramic typically densified from its original dimension about quarter to half when sintering process takes places due to particle adherence create shrinking of global body of ceramic [16].

\subsection{Microstructural Analysis}

The formation of glass phase, porosity and quartz relict also can be seen from this section. Fig. 6 and Fig. 7 display the microstructure image of sintered sample at $900^{\circ} \mathrm{C}$ and $1200^{\circ} \mathrm{C}$ for all composition.

i. Sintering temperature of $900^{\circ} \mathrm{C}$ : It can be observed from the Fig. 6 that sample contains partially quartz relict and there are no formation of glassy phase occurs. The formation of open porosity can be seen plenty which prompt a large size of porosity. Moreover, the incomplete grain growth triggered a scatter quartz formation which can be correlated with the result of volume shrinkage. Lower sintering temperature reduce the interaction of particle-particle and creates the separation distance between particle which produce a void [17]. Less contact of particle resulting low shrinkage occurrence to the whole sample.

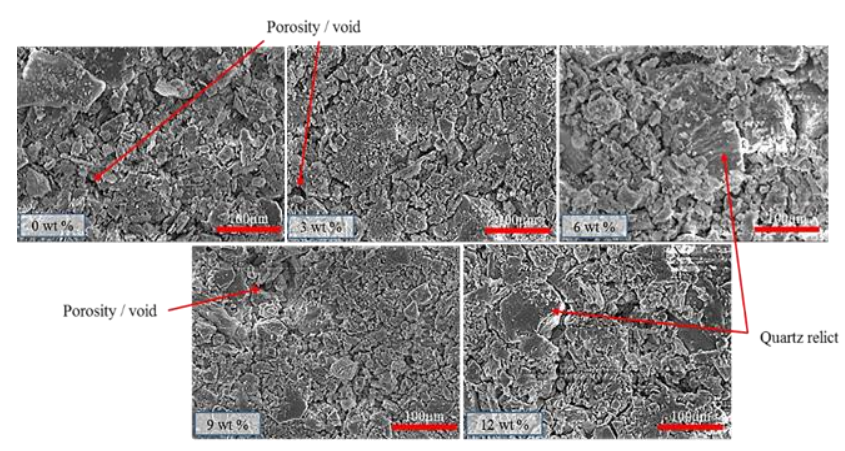

Fig. 6 Microstructural morphology of sample sintered at $900^{\circ} \mathrm{C}$ for all composition ii. Sintering temperature of $1^{200} \mathrm{C}$ : Fig. 7 differentiate microstructure morphology construct from vary temperature. The images reveal the occurrence of complete vitrification where the elimination of porosity generates a dense body to the sample. The formation of glassy phase can be seen a lot which closes the open pores. This is due to the melting of the AR glass resulting high viscosity in liquid phase to penetrated the pores and separate neighbor pores [17]. The result is correlated with TG and DT graph where mass gained cause by vitrification process as well as endothermic reaction occurrence. The image of $12 \mathrm{wt} \%$ AR glass addition manifest the occurrence of least porosity and the body was densified. This image can be associated with the result of higher shrinkage gained caused by complete densification.

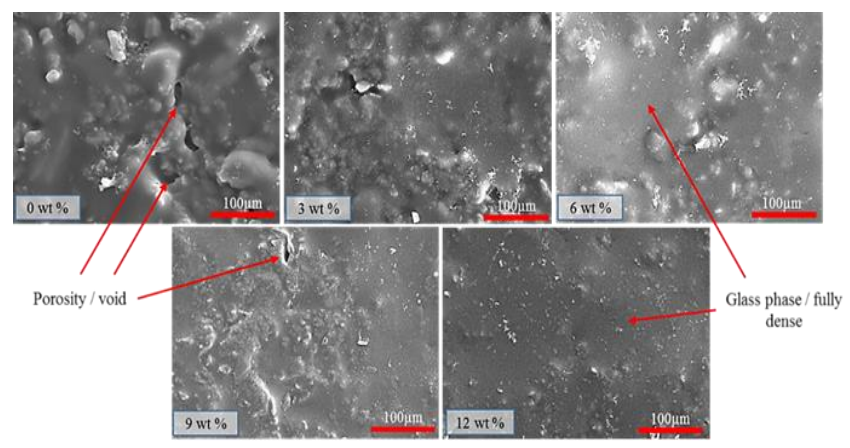

Fig. 7 Microstructural morphology of sample sintered at $1200^{\circ} \mathrm{C}$ for all composition

\section{Conclusion}

Based on the result revealed at previous section, the effect of sintering temperature and AR glass addition towards porcelain clay was successfully demonstrated by volume shrinkage and thermal changes. TG and DT graph shows that the significant temperature for sintering process starts to occur between $900^{\circ} \mathrm{C}$ and $1200^{\circ} \mathrm{C}$ where the different of amount can be seen. As discussed in volume shrinkage, the addition of AR glass can be seen assist a higher volume shrinkage to the porcelain body in which the favorable shrinkage occurred with $9 \mathrm{wt} \%$ of AR glass addition at $1100^{\circ} \mathrm{C}$ and $1200^{\circ} \mathrm{C}$. Besides that, the morphology of samples proved that the sample sintered at $1200^{\circ} \mathrm{C}$ shows a vitrification occurrence and display least porosity or void. Thus, it can be considered that the increasing of sintering temperature and addition of AR glass is affecting physical properties of porcelain clay and significant in manufacturing clay pipes for sewer application.

\section{Acknowledgement}

The authors would like to thanks to the Centre of Graduates Studies, Universiti Tun Hussein Onn Malaysia (UTHM) because this paper was partly sponsored by Centre of Graduates Studies. This research was sponsored by UTHM Contract Grant U553. 


\section{References}

[1] R. Salha and F. V Tosa, Looking for Oil-free Building Materials Clay Pipes to Replace Polymer Pipes, Procedia Technol., vol. 22, no. October 2015, pp. 343-350, 2016.

[2] M. P. Groover, Fundamentals of Modern Manufacturing. Materials, Process and Systems, Fourth Edi., vol. 4. John Wiley \& Sons, Inc, 2010.

[3] A. T. Ring, Fundamentals of Ceramic Powder Processing and Synthesis. Elsevier Inc., 1996.

[4] G. Barluenga and F. Hernández-olivares, Cracking control of concretes modified with short AR-glass fibers at early age . Experimental results on standard concrete and SCC, vol. 37, pp. 1624-1638, 2007.

[5] B. H. A. Bakar, M. H. W. Ibrahim, and M. A. M. Johari, A Review : Durability of Fired Clay Brick Masonry Wall due to Salt Attack, Int. J. Integr. Eng. (Issue Civ. Environ. Eng., vol. 1, no. 2, 2009.

[6] D. Richerson, D. W. Richerson, and W. E. Lee, Modern Ceramic Engineering: Properties, Processing, and Use in Design, Third Edition. Taylor \& Francis, 2005.

[7] C. Rothe and R. Plonka, Nano Surface Structuring Of Alkali-Resistant Glass Fibres For Multifunctional Effects Methods, In 1st International Conference Textile Reinforced Concrete, 2006, pp. 67-76.

[8] A. J. Ajala and N. A. Badarulzaman, Performance Assessment of Physico-Mechanical Properties of Aloji Fireclay Brick, Int. J. Integr. Eng., vol. 8, no. 2, pp. 13-15, 2016.

[9] A. C. P. Galvao, A. C. M. Farias, and J. U. L.
Mendes, Characterization of waste of soda-lime glass generated from lapping process to reuse as filler in composite materials as thermal insulation, Ceramica, vol. 61, pp. 367-373, 2015.

[10] M. Romero, J. Martín-Márquez, J. Ma. Rincón and M. Romero, Effect of firing temperature on sintering of porcelain stoneware tiles, vol. 34, pp. 1867-1873, 2008.

[11] H. Goring, Pottery Making Illustrated, The American Ceramic Society. Charlie Spahr, 2015.

[12] S. Ferrer and A. Mezquita, Estimation of the heat of reaction in traditional ceramic compositions, Appl. Clay Sci., vol. 108, no. May, 2015.

[13] A. J. Souza, B. C. A. Pinheiro, and J. N. F. Holanda, Sintering Behavior of Vitrified Ceramic Tiles Incorporated with Petroleum Waste, Sintering Applications. InTech, p. 73, 2013.

[14] S. Maity and B. K. Sarka, Development of HighStrength Whiteware Bodies, J. Eur. Ceram. Soc. 16, vol. 2219, no. 96, 1996.

[15] E. Bernardo, L. Esposito, E. Rambaldi, A. Tucci, and S. Hreglich, Recycle of waste glass into 'glass-ceramic stoneware, J. Am. Ceram. Soc., vol. 91, no. 7, pp. 2156-2162, 2008.

[16] G. Eyring, Advanced Materials by Design, Congr. United States - Off. Technol. Assess., no. June, 1988.

[17] M. Salehi and A. Salem, Porosity-strength correlations in ceramic Raschig ring: Effects of sintering temperature and water content, Int. J. Appl. Ceram. Technol., vol. 7, no. 6, pp. 918924, 2010. 